\title{
Enzyme-linked immunosorbent assay and Western blot antibody determination in sera from patients diagnosed with different helminthic infections with Anisakis simplex antigen purified by affinity chromatography
}

\author{
M Rodero, T Chivato*, A Muro**, C Cuéllar/+
}

\begin{abstract}
Departamento de Parasitología, Facultad de Farmacia, Universidad Complutense, 28040 Madrid, España *Servicio de Alergia e Inmunología, Hospital del Aire, Madrid, España **Laboratorio de Parasitología, Facultad de Farmacia, Universidad de Salamanca, Salamanca, España
\end{abstract}

An evaluation of the sensitivity and the specificity of the Anisakis simplex antigens purified by affinity chromatography was performed using sera from patients diagnosed with Anisakis sensitisation and sera from patients previously diagnosed with different helminthic infections. Only the sera of the patients diagnosed with Schistosoma mansoni or Onchocerca volvulus parasitic infections were negative against the A. simplex antigen and its purified fractions (PAK antigen: A. simplex antigen purified using columns prepared with anti-A. simplex rabbit IgG and PAS antigen: PAK antigen purified using columns prepared with anti-Ascaris suum rabbit IgG). However all the sera were positive against the A. suum antigen. In all the sera from the patients diagnosed with Anisakis sensitisation, the antibody levels detected using the purified antigens (PAK and PAS antigens) were lower than the observed using the A. simplex crude extract with the highest diminution in the case of the IgG. When these same sera were tested against the A. simplex crude extract by Western blot, several bands of high molecular masses were observed as well as, intense bands at 60 and/or $40 \mathrm{kDa}$. A concentration of these last proteins was observed in the PAK and the PAS antigens. When the sensitivity and the specificity determinations were performed, only seven of the 38 patients diagnosed of Anisakis sensitisation were positive, as well as, the sera from the patients diagnosed with parasitisms by Echinococcus granulosus or Fasciola hepatica.

Key words: Anisakis simplex - enzyme-linked immunosorbent assay - Western blot - helminthoses - cross-reactivity

Anisakidosis is a human disease caused by the ingestion of larval nematodes from the family Anisakidae, especially Anisakis simplex. The infection is acquired by eating raw seafood or undercooked fish and squid (Sakanari \& McKerrow 1989). Anisakidosis is divided into gastric, intestinal, and ectopic (Ishikura et al. 1993). Due to the vagueness of the symptoms, this disease is often misdiagnosed as appendicitis, acute abdomen, gastric tumor or cancer, ileitis, cholecystitis, diverticulitis, tuberculous peritonitis, cancer of the pancreas or Chrohn's disease (Sakanari \& McKerrow 1989).

Immunodiagnostic methods have been developed, but several cross-reactivities have been observed. Although, the introduction of sensitive techniques, such as enzymelinked immunosorbent assay (ELISA) did not avoid the presence of antibodies that provoke cross-reactivities with Ascaris and Toxocara (Kennedy et al. 1988) when the A. simplex larval crude extract was used as reactive for the determination of specific IgE levels in patients with suspected anisakidosis, so by fluoro enzymo immuno assay (FEIA), immunoblot or prick test, due to the high proportion of false negative results detected (Lorenzo et al. 2000).

${ }^{+}$Corresponding author. E-mail: cuellarh@farm.ucm.es Received 14 June 2004

Accepted 14 March 2005
In fact, extensive homology between both somatic and excretory-secretory antigens of $A$. simplex and other ascaridoid nematodes mainly A. suum, A. lumbricoides, and T. canis has been reported (Kennedy et al. 1988).

For these reasons, in this work, an evaluation of the sensitivity and the specificity of the A. simplex antigen purified by affinity chromatography (Rodero et al. 2001, 2002) was carried out using sera from patients previously diagnosed with Anisakis sensitisation and different helminthic infections.

\section{MATERIALSAND METHODS}

Parasites - A. simplex L3 were picked up manually from the viscera, flesh, and body cavities of naturally infected blue whiting (Micromesistius poutassou) and exhaustively washed in water (Perteguer \& Cuéllar 1998). A. suum were obtained from swine natural infections (Guillén et al. 1986).

Antigens - For the preparation of the crude extract (CE) of A. simplex (A. simplex $\mathrm{CE}$ antigen or $\mathrm{AK}$ antigen), L3 were placed at $4^{\circ} \mathrm{C}$ in phosphate-buffered saline (PBS). This material was homogenised in a hand-operated glass tissue grinder at $4^{\circ} \mathrm{C}$, followed by sonication with a Virsonic (Virtis, NY, US) set at 70\% output power. The homogenate was extracted in PBS at $4^{\circ} \mathrm{C}$ overnight and, subsequently, delipidised with n-hexane and then centrifuged at $8497 \mathrm{~g}$ for $30 \mathrm{~min}$ at $4^{\circ} \mathrm{C}$ (Biofuge 17RS: Heraeus Sepatech, Gmb, Osterode, Denmark). The supernatant was dyalised overnight at $4^{\circ} \mathrm{C}$ in PBS. The protein content of the extract was 
estimated and the extract was frozen at $20^{\circ} \mathrm{C}$ until used (Perteguer \& Cuéllar 1998). The antigen from A. suum adults (A. suum $\mathrm{CE}$ antigen or AS antigen) was obtained using a modification of the Welch et al. (1983) method by homogenisation and extraction in PBS at $4^{\circ} \mathrm{C}$ overnight (instead of ultrasonic burst). Its protein content was estimated by the Bradford (1976) method, and then the antigen was frozen at $20^{\circ} \mathrm{C}$ until use (Águila et al. 1987, Cuéllar et al. 1990).

Hyperimmune sera - New Zealand rabbits of about 3 $\mathrm{kg}$ body weight were immunised with $1 \mathrm{mg}$ of larval $A$. simplex or adult $A$. suum $\mathrm{CE}$ antigens by the intramuscular route. The animals were bled weekly postimmunization (p.i.) after the first inoculation (week 0) (García-Palacios et al. 1996). The experiments were carried out according to the European Council on applied animals experiments, published in the Guidelines 86/609ED, and controlled in Spain by Royal Decree 223/1988 of 14 March, on the protection of animals used for research and other scientific ends.

Human sera - Thirty-eight human anti-Anisakis sera were obtained from the Servicio de Alergia del Hospital del Aire de Madrid. The concentration of circulating antiAnisakis IgE antibodies was measured by means of the Pharmacia CAP System RAST FEIA (Pharmacia AB, Uppsala, Sweden). The results of this fluoro immuno assay were reported in $\mathrm{kU} / \mathrm{l}$ and converted to CAP "scores" of $0(<0.35), 1(0.35-0.7), 2(0.7-3.5), 3(3.5$ - 17.5), 4 (17.5 $-50), 5(50-100)$ and $6(>100)$. All the sera showed positive CAP values to Anisakis by FEIA, which varied from values of $\mathrm{CAP}=1(3 \%), \mathrm{CAP}=2(26 \%), \mathrm{CAP}=3(47 \%), \mathrm{CAP}$ $=4(10 \%), \mathrm{CAP}=5(8 \%)$ and to $\mathrm{CAP}=6(5 \%)$. Nine sera from patients diagnosed with Loa loa, Onchocerca volvulus, A. lumbricoides, Trichuris trichiura, T. canis, S. mansoni, S. intercalatum, Echinococcus granulosus and Fasciola hepatica parasitic infections were selected.

Purification of antigens by affinity chromatography - Protein A-Sepharose CL-4B beads (Pharmacia Biotech) columns were prepared according to the manufacturer's intructions. Anti-A. simplex or -A. suum rabbit antibodies, in sample buffer $0.05 \mathrm{M}$ Tris, $0.5 \mathrm{M} \mathrm{NaCl}, \mathrm{pH} 8.0$ were loaded into the columns. Fractions of $1 \mathrm{ml}$ were then collected. Unbound immunoglobulins were washed with washing buffer ( $0.05 \mathrm{M}$ Tris, $0.5 \mathrm{M} \mathrm{NaCl}, \mathrm{pH} 8.0)$. Bound immunoglobulins then were eluted with glycine buffer $(0.2$ $\mathrm{M}$ glycine, $0.5 \mathrm{M} \mathrm{NaCl}, \mathrm{pH} 2.8$ ). Fractions were collected onto $100 \mu \mathrm{l}$ of collection buffer (Tris-base $1 \mathrm{M}, \mathrm{pH} 8.5$ ) and read on a spectrophotometer at $\mathrm{A}_{280}$ for calculating $\mathrm{IgG}$ concentration. A column was prepared with protein $\mathrm{A}$ affinity isolated anti-A. simplex $\mathrm{IgG}$, at a concentration of $5 \mathrm{mg} / \mathrm{ml}$ in $\mathrm{NaHCO}_{3} 0.1 \mathrm{M}$ with $\mathrm{NaCl} 0.5 \mathrm{M}, \mathrm{pH} 8.5$ coupled to $\mathrm{CNBr}$-activated Sepharose 4B according to the manufacturer's instructions (Pharmacia Biotech). The A. simplex $\mathrm{CE}$ antigen in sample buffer was loaded into the column and incubated $3 \mathrm{~h}$ at room temperature. Fractions of $1 \mathrm{ml}$ were then collected. Unbound antigens were washed with washing buffer and bound antigens were eluted with glycine buffer followed by $50 \mathrm{mM}$ diethylamine in saline, $\mathrm{pH} 11.5$ collected into glycine to neutralise the eluted fractions. Fractions were read at $\mathrm{A}_{280}$. This antigen was named as A. simplex PAK antigen. The same procedure was carried out using columns prepared with rabbit anti-A. suum IgG, obtaining the A. simplex PAS antigen and the A. simplex EAS antigen. In summary: PAK (A. simplex $\mathrm{CE}$ antigen eluted from $\mathrm{CNBr}$-activated Sepharose 4B coupled to IgG from rabbits immunised with A. simplex CE antigen), PAS (A. simplex PAK antigen after loading into a $\mathrm{CNBr}$-activated Sepharose $4 \mathrm{~B}$ coupled to $\mathrm{IgG}$ from rabbits immunised with adult $A$. suum $\mathrm{CE}$ antigen) and EAS (A. simplex PAK antigen eluted from the anti-A. suum column).

Immunoblot - Sodium dodecylsulphate-polyacrilamide gel electrophoresis (SDS-PAGE) was carried out as described by Laemmli (1970) and revised by Hames (1986) using a Mini Protean ${ }^{\circledR}$ III cell (Bio Rad). The gels consisted of a $4 \%$ stacking gel and 5-20\% gradient separating gel. Samples were dissolved in a sample buffer $(50 \mathrm{mM}$ Tris-HCl buffer, $\mathrm{pH} 8.6$, containing 2\% SDS, 20\% glycerol, and $0.02 \%$ bromophenol blue) diluted $1: 1$ in electrode buffer (25 mM Tris, $192 \mathrm{mM}$ glycine, $\mathrm{pH}$ 8.3), containing $1 \%$ SDS. Electrophoresis was performed for $2 \mathrm{~h}$ at a constant $100 \mathrm{~V}$ in Tris-glycine electrode buffer (see above). Broad range molecular mass markers (6.5 - 205 or 7.2 - 209 $\mathrm{kDa}, \mathrm{Bio} \mathrm{Rad}$ ) were incorporated into each electrophoresis run. Gels were stained with $\mathrm{AgNO}_{3}$. Following the SDSPAGE of antigens, the protein bands were transferred onto a $0.22 \mu \mathrm{m}$ pore size nitrocellulose membrane (Pharmacia) in a Mini Trans-blot Electrophoretic Transfer Cell (Bio Rad) with $25 \mathrm{mM}$ Tris, $192 \mathrm{mM}$ glycine, 20\% v/v methanol, $\mathrm{pH}$ 8.3. The transblot was carried out at a constant $100 \mathrm{~V}$ for $1 \mathrm{~h}$. The membrane was blocked for $3 \mathrm{~h}$ at room temperature with PBS containig 5\% non-fat dry milk, prior to immunorecognition by incubation for $2 \mathrm{~h}$ with the human sera diluted in PBS-Tween containing $1 \%$ non-fat dry milk. Each paper was then washed with PBS-Tween 20 $(3 \times 5 \mathrm{~min})$ and incubated for $3 \mathrm{~h}$ with goat anti-human Ig's (total immunoglobulins), IgM, IgG or IgA, HRP conjugate (Biosource International, Camarillo, CA, US), at the appropriate dilution in PBS-Tween 20, containing $1 \%$ nonfat dry milk. To visualize bands the nitrocellulose was washed with PBS-Tween $20(3 \times 5 \mathrm{~min})$ and reacted with the substrate (PBS, containing $0.006 \% \mathrm{H}_{2} \mathrm{O}_{2}$ methanol, containing $0.03 \%$ 4-chloro-1-naftol). The reaction was stopped by exhaustive washing with distilled water.

Determination of specific antibody levels - The antibody levels were measured by indirect ELISA. The 96 well microtitre plates (Nunc-Immuno Plate PolySorp ${ }^{\mathrm{TM}}$ ) were sensitised overnight at $4^{\circ} \mathrm{C}$ by the addition of $100 \mu \mathrm{l} /$ well of antigens diluted at $1 \mu \mathrm{g} / \mathrm{ml}$ in a $0.1 \mathrm{M}$ carbonate buffer, $\mathrm{pH}$ 9.6. After washing three times with $0.05 \%$ PBSTween 20 (PBS-Tween), wells were blocked by the addition of $200 \mu \mathrm{l}$ per well of $0.1 \% \mathrm{BSA}$ in PBS, for $1 \mathrm{~h}$ at $37^{\circ} \mathrm{C}$. After washing, $100 \mu \mathrm{l}$ of duplicate dilutions of human sera at $1 / 400$ in PBS-Tween, containing $0.1 \%$ BSA were added and incubated at $37^{\circ} \mathrm{C}$ for $2 \mathrm{~h}$. Once the plates were washed, $100 \mu \mathrm{l}$ per well of goat anti-human Ig's (total immunoglobulins), IgM, IgG or IgA, HRP conjugate (Biosource International, Camarillo, CA, US), at the appropriate dilu- 
tion in PBS-Tween, $0.1 \% \mathrm{BSA}$, were incubated for $1 \mathrm{~h}$ at $37^{\circ} \mathrm{C}$. After adding substrate (phosphate citrate buffer, containing $0.04 \% \mathrm{H}_{2} \mathrm{O}_{2}$ and $0.04 \%$ o-phenylenediamine) the reaction was stopped with $3 \mathrm{~N}$ sulphuric acid and the plates were read at $490 \mathrm{~nm}$ (García-Palacios et al. 1996). Results were expressed as O.D.p-O.D.c indexes by subtracting the mean optical density (O.D.) of the control from the mean O.D. of the test sera once the non-specific reaction with the BSA used in the blocking was subtracted.

Determination of the sensitivity and the specificity of the A. simplex crude extract and the PAK and PAS purified antigens with sera from patients diagnosed with Anisakis sensitisation - For the determination of the sensitivity and the specificity of the different antigens, $2 \times 2$ tables were carried out. In these tables, the number of sera from patients diagnosed with Anisakis sensitisation and CAP values $\geq 3$ and $\leq 2$ against the different antigens were represented for each immunoglobulin (Ig's, IgG, IgM, $\operatorname{IgA}, \operatorname{IgE})$. Further, different O.D. cutting points were selected in function of the positive and negative predictive values, as well as, the sensitivity and the specificity, in the case of each assayed immunoglobulins and antigens (AK, PAK, and PAS) (Fig. 3).

\section{RESULTS}

ELISA antibody determinations in the sera from patients diagnosed with Anisakis sensitisation using A. simplex antigens purified by affinity chromatography - Thirtyeight sera obtained from the Servicio de Alergia del Hospital del Aire de Madrid were assayed. All the sera showed positive CAP values to Anisakis by FEIA, which varied from values of $\mathrm{CAP}=1(3 \%), \mathrm{CAP}=2(26 \%), \mathrm{CAP}=3$ $(47 \%), \mathrm{CAP}=4(10 \%), \mathrm{CAP}=5(8 \%)$, to $\mathrm{CAP}=6(5 \%)$.

The 96 well microtiter plates were coated with $100 \mu \mathrm{l} /$ well $(1 \mu \mathrm{g} / \mathrm{ml})$ of the crude extract (CE) antigens of A. simplex or A. suum (AK and AS antigens), as well as, the antigens purified using the columns of anti-A. simplex or anti-A. suum IgG (PAK and PAS antigens, respectively) and the antigen eluted from the latest column (EAS antigen). The sera were diluted at $1 / 400$, and, after their incubation, the Ig's, IgM, IgG and IgA were measured. The mean O.D. were calculated after the subtraction of the BSA and negative control values.

With all the assayed sera from the patients diagnosed with Anisakis sensitisation, the highest values were obtained when the ELISA test were performed against the $A$. simplex $\mathrm{CE}$ (AK antigen). The IgG was the most abundant immunoglobulin, followed by the IgM and the Ig's, whilst the lowest values were observed in the case of the IgA (Fig. 1).

When the sera were tested against the A. suum crude extract (AS antigen) $45 \%$ of them showed values equal or superior than 0.2 in the case of the specific Ig's were detected. Contrarily, these values were modified when the $\mathrm{IgG}$ antibodies were tested. In this case, $24 \%$ of the sera showed anti-A. suum IgG levels equal or superior than 0.2 . On the other hand, IgM values were detected in $39 \%$ of the sera. In the case of the IgA, the levels were lower, because only $13 \%$ of the sera showed O.D. values equal or higher than 0.15 (Fig.1).
When the sera were tested against the purified antigenic fractions (PAK and PAS antigens), in both cases, the highest values were observed when the IgM immunoglobulins were tested, followed by the Ig's and the IgG. Finally, the lowest values belonged to the IgA.

All the detected O.D. values using the purified preparations (PAK and PAS antigens) were lower than the observed using the A. simplex CE (AK antigen) with the highest diminution in the case of the $\operatorname{IgG}(0.36-0.08 / \mathrm{AK}$ PAS antigens).

When the sera were tested against the "eluted of Ascaris" (EAS antigen) the mean values of the $\mathrm{IgG}$ increased (O.D. $=0.26)$ compared to the observed using the purified antigens (Fig. 1).

ELISA antibody determinations in the sera from patients diagnosed with different helminth parasitic infections using A. simplex antigens purified by affinity chromatography - The evaluation by ELISA of the A. simplex larval antigens purified by affinity chromatography was completed using sera from patients diagnosed with $L$. loa, $O$. volvulus, A. lumbricoides, T. trichiura, T. canis, $S$. mansoni, S. intercalatum, E. granulosus, and F. hepatica.

These sera were tested against the CE antigens of $A$. simplex (AK antigen) and A. suum (AS antigen), as well as the antigen eluted from the column of anti- $A$ simplex rabbit IgG (PAK antigen), the $A$. simplex antigen purifed by the column of anti-A. suum rabbit IgG (PAS antigen), and the eluted from the mentioned column (EAS antigen). The specific Ig's, IgG, IgM, and IgA were measured.

Only the sera from the patients diagnosed with $S$. mansoni or $O$. volvulus parasitic infections were negative against the $A$. simplex antigen (AK antigen) and its purified fractions (PAK, PAS, and EAS antigen). However, all the sera showed cross-reactions with the A. suum one (AS antigen) when the Ig's, IgG, IgM and IgA antibodies were measured (Table I).

When the PAK antigen were tested, in all the patients, except $O$. volvulus, A. lumbricoides, and $S$. mansoni cases, the $\mathrm{IgG}$ levels enhanced with respect to the A. simplex antigen (AK antigen). On the contrary, when the sera were tested against the PAS antigen, the IgG levels suffered a reduction higher than $50 \%$ for the T. trichiura, S. intercalatum, and E. granulosus patients and were negative for the $O$. volvulus, A. lumbricoides, and $S$. mansoni patients. Finally, when the EAS antigen was tested, the IgG levels enhanced more than twice with respect to the PAS antigen in the case of the T. trichiura, S. intercalatum, E. granulosus, and F. hepatica patients. The IgM levels unchanged with respect to the PAS antigen, as well as, the total immunoglobulins (Table I).

Western blot antibody determinations in the sera from patients diagnosed with different helminth parasitic infections using A. simplex antigens purified by affinity chromatography - When the sera were tested against the A. simplex antigen, all the sera except the $O$. volvulus case, reacted with proteins of high molecular masses (> $84 \mathrm{kDa}$ ). The sera from the L. loa, A. lumbricoides, and S. mansoni patients reacted with the $60 \mathrm{kDa}$ protein. These same sera also reacted with a $40 \mathrm{kDa}$ protein, as well as, the sera from T. trichiura, T. canis, and S. intercalatum 

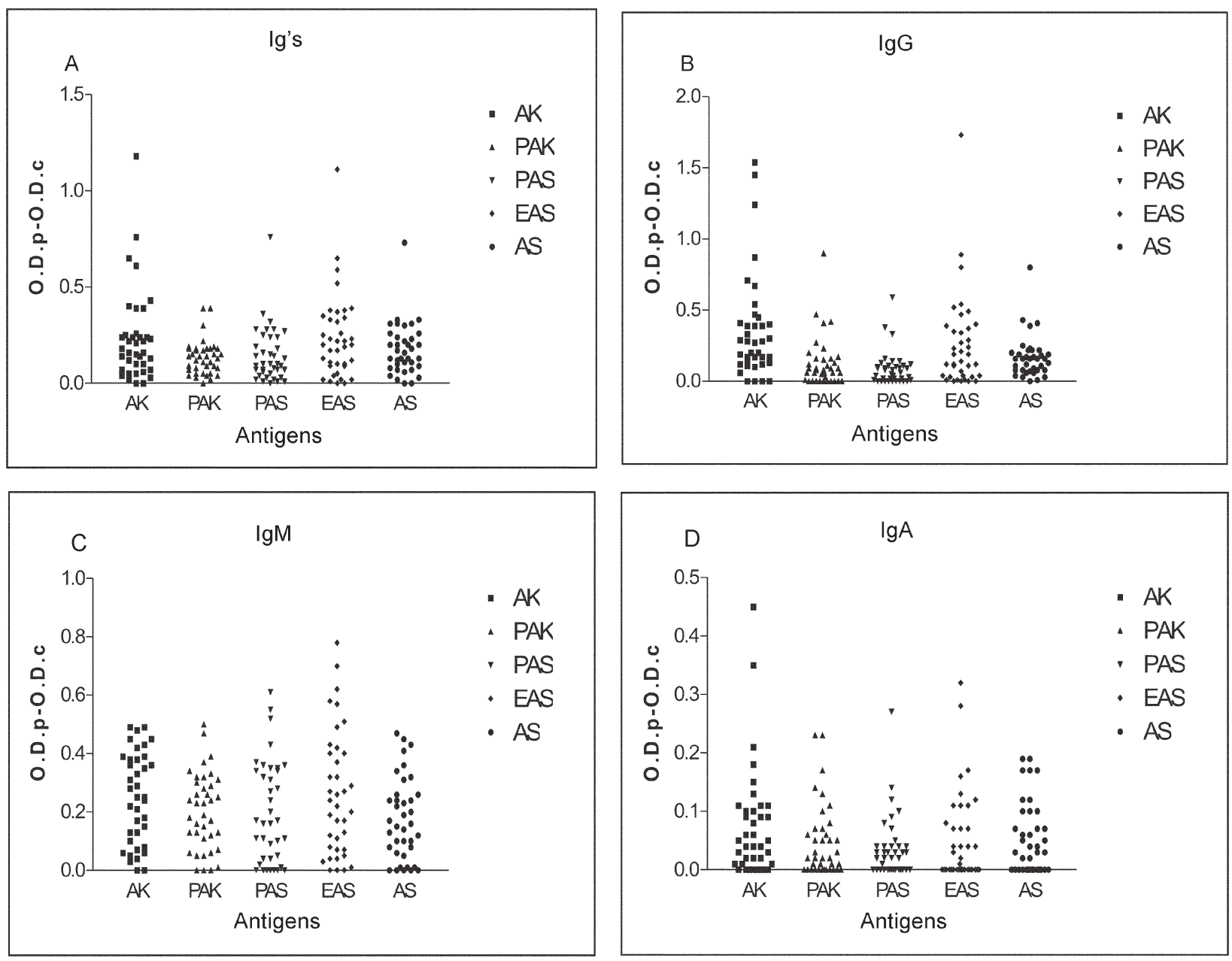

Fig. 1: Ig's (A), IgG (B), IgM (C), and IgA (D) levels in sera from patients diagnosed with Anisakis sensitisation against crude extract of A. simplex (AK antigen), Ascaris suum (AS antigen), and purified antigens PAK, PAS and EAS.

patients, while the $32 \mathrm{kDa}$ protein only was immunorecognised for the $F$. hepatica serum. When the sera were tested against the PAK antigen, the immunorecognition against the $60 \mathrm{kDa}$ protein enhanced in intensity in the case of the L. loa and A. lumbricoides sera. This reaction disappeared with the $S$. mansoni serum and appeared using the T. canis, E. granulosus, and F. hepatica sera. In addition, in this last patient, the immunorecognition against the $32 \mathrm{kDa}$ protein disappeared. Against the PAS antigen, only was immunorecogniton of the $60 \mathrm{kDa}$ protein in the case of the L. loa, A. lumbricoides, and T. canis sera (Fig. 2).

Determination of the sensitivity and the specificity of the A. simplex crude extract and the PAK and PAS purified antigens with sera from patients diagnosed with $A$. simplex sensitisation - When the A. simplex crude extract was used, variations of the sensitivity and the specificity were detected according to the selected immunoglobulin. The cut point of O.D. $\geq 0.15$ for the IgG was selected as a first reference because this immunoglobulin showed the greatest sensitivity $(82.7 \%)$. When this parameter was applied, $70 \%$ of the patients diagnosed with A. simplex sensitisation were positive. When the second determination was performed by using the PAK antigen and the cut point of O.D. $\geq 0.07$ for the IgG, a decrease of $20 \%$ in the positive group was produced. Finally, the cut point of O.D. $\geq 0.05$ for the IgA was selected against the PAS antigen. Only seven of the 38 tested sera were positive (Table II).

When these three parameters were applied to the sera from the patients diagnosed with several parasitic infections, only the sera from the patients diagnosed with parasitisms of E. granulosus and $F$. hepatica were positive.

\section{DISCUSSION}

In this work, the specificity and the sensitivity of the A. simplex antigen purified by affinity chromatography previously described (Rodero et al. 2001, 2002), were evaluated by ELISA, using sera from patients previously diagnosed with several parasitic infections.

When the different immunoglobulins (Ig's, $\operatorname{IgG}, \operatorname{IgM}$, 


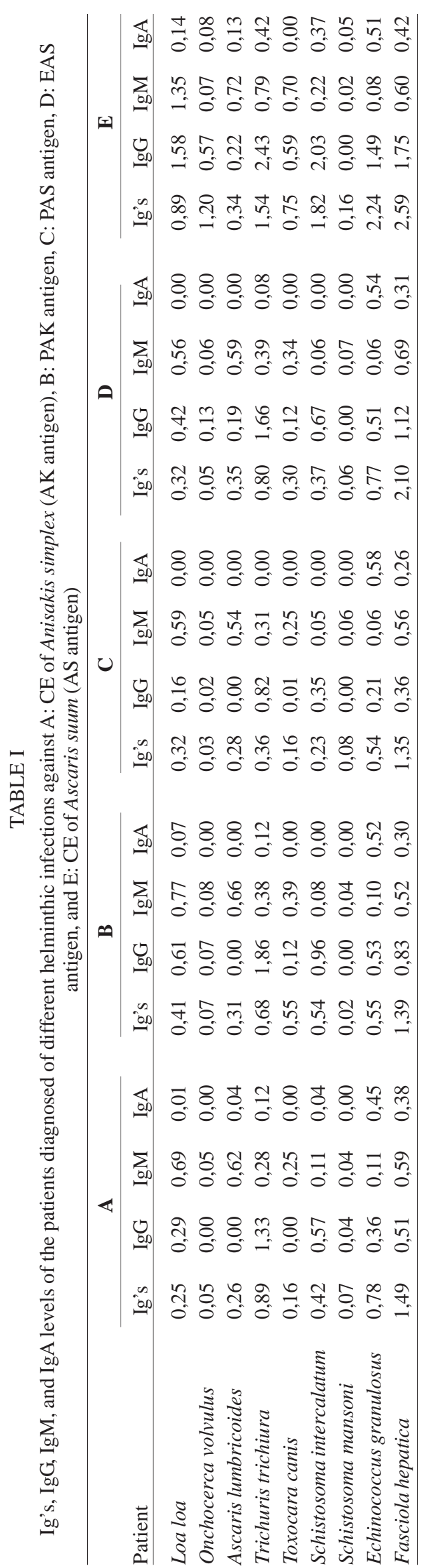

TABLE II

Positive human sera ( $($ ) against Anisakis simplex AK, PAK, and PAS antigens for the different cut points selected

\begin{tabular}{|c|c|c|c|}
\hline \multirow[b]{2}{*}{ Patient/CAP } & \multicolumn{3}{|c|}{ Cut point } \\
\hline & $\begin{array}{c}\mathrm{AK} \\
\mathrm{IgG} \geq 0,15\end{array}$ & $\begin{array}{c}\text { PAK } \\
\operatorname{IgG} \geq 0,07\end{array}$ & $\begin{array}{c}\text { PAS } \\
\operatorname{IgA} \geq 0,05\end{array}$ \\
\hline \multicolumn{4}{|l|}{$2936 / 2$} \\
\hline $3056 / 3$ & * & $\star$ & \\
\hline $3423 / 3$ & $\star$ & & \\
\hline $3461 / 3$ & $\star$ & $\star$ & \\
\hline $3475 / 3$ & * & $\star$ & \\
\hline \multicolumn{4}{|l|}{$3500 / 3$} \\
\hline $3524 / 3$ & $\star$ & $\star$ & $\star$ \\
\hline $3530 / 2$ & $\star$ & & \\
\hline $3544 / 3$ & * & & \\
\hline \multicolumn{4}{|l|}{$3604 / 3$} \\
\hline $3619 / 3$ & $\star$ & $\star$ & $\star$ \\
\hline \multicolumn{4}{|l|}{$3638 / 4$} \\
\hline \multicolumn{4}{|l|}{$3679 / 5$} \\
\hline $3720 / 1$ & * & $\star$ & \\
\hline $3755 / 2$ & * & & \\
\hline $3782 / 3$ & $\star$ & $\star$ & $\star$ \\
\hline $3801 / 6$ & $\star$ & $\star$ & \\
\hline $3807 / 2$ & * & & \\
\hline $3837 / 2$ & * & $\star$ & $\star$ \\
\hline $3857 / 3$ & $\star$ & $\star$ & \\
\hline $3866 / 5$ & * & & \\
\hline $3878 / 3$ & * & $\star$ & \\
\hline \multicolumn{4}{|l|}{$3883 / 2$} \\
\hline $3884 / 3$ & * & $\star$ & \\
\hline $3903 / 3$ & * & & \\
\hline $3906 / 4$ & * & $\star$ & \\
\hline \multicolumn{4}{|l|}{$3913 / 2$} \\
\hline $3914 / 3$ & * & & \\
\hline $3938 / 3$ & $\star$ & & \\
\hline $3949 / 3$ & * & & \\
\hline $3975 / 2$ & & $\star$ & \\
\hline $3990 / 6$ & $\star$ & $\star$ & $\star$ \\
\hline $4009 / 4$ & * & $\star$ & * \\
\hline $4016 / 3$ & $\star$ & $\star$ & $\star$ \\
\hline \multicolumn{4}{|l|}{$4118 / 4$} \\
\hline $4153 / 2$ & * & $\star$ & \\
\hline $4159 / 5$ & $\star$ & $\star$ & \\
\hline $4189 / 2$ & & $\star$ & \\
\hline Total & 28 & 20 & 7 \\
\hline
\end{tabular}

$\operatorname{IgA}$ ) were tested by ELISA, against the A. simplex antigen, as well as, its purified fractions, only the sera from the patients diagnosed with $S$. mansoni or $O$. volvulus infections were negative. These results were maintained using the serum from an $O$. volvulus patient when assayed by Western blot as a diagnostic method. Any immunoreactive band did not appear when the total immunoglobulins were tested. However, the S. mansoni patient serum showed several bands of high molecular masses against the $A$. simplex antigen (AK antigen) and others immunoreactive bands of around 60 and $40 \mathrm{kDa}$.

This difference between the antibody determination using both techniques (ELISA and Western blot), could be due to the different techniques and metodologies utilised in order to determine the different immunoglobu- 
lin class levels, like the serum dilution, as well as, the antigenic concentration.

Noya et al. (1995) detected $\operatorname{IgG}, \operatorname{IgM}, \operatorname{Ig} A$, and $\operatorname{IgE}$ specific antibodies by ELISA when tested the sera of 30 S. mansoni infected children, while, by Western blot, appeared reactive bands of high molecular masses, as well as, 45,36 , and $30 \mathrm{kDa}$ for IgG and $77 \mathrm{kDa}$ for IgM antibod-

A

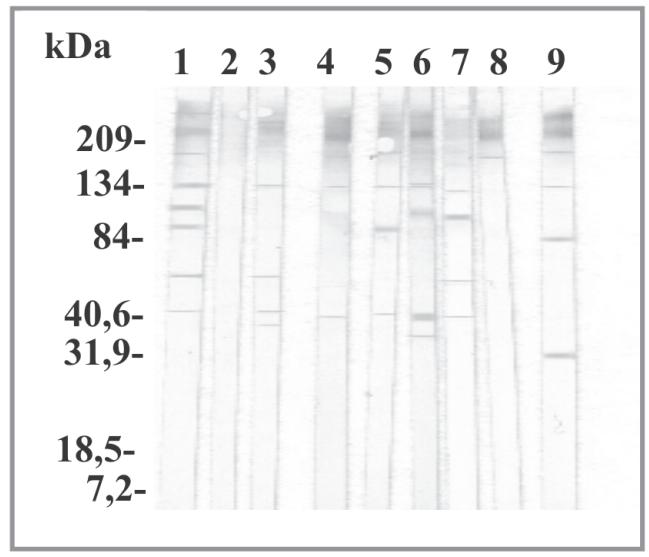

C

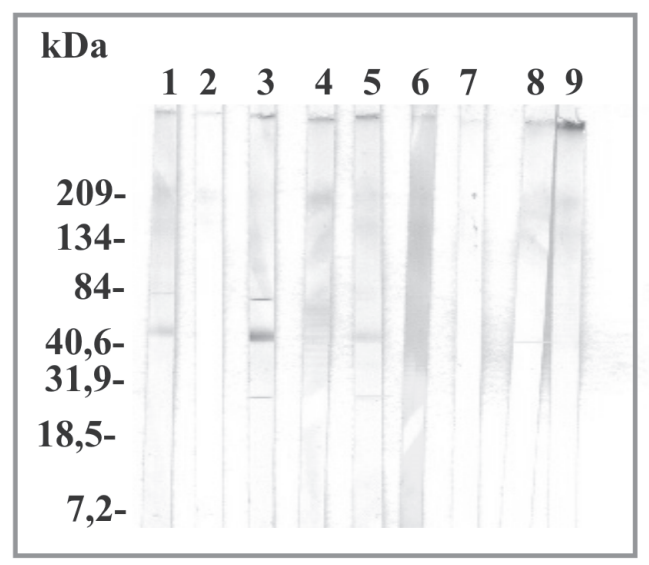

$\mathbf{E}$

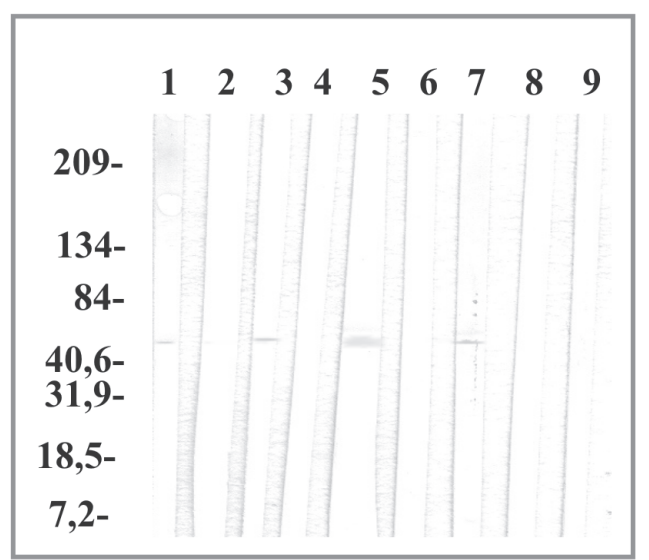

ies, indicating that the $36 \mathrm{kDa}$ protein was usefull for immunodiagnostic. In the case of $S$. intercalatum the results obtained, in our experimental conditions, were completely different. High levels of Ig's and IgG antibodies, and basal levels for IgM and IgA were detected by ELISA. These diferences among immunoglobulins could be due to the different parasitic locations in function of the infec-

\section{B}

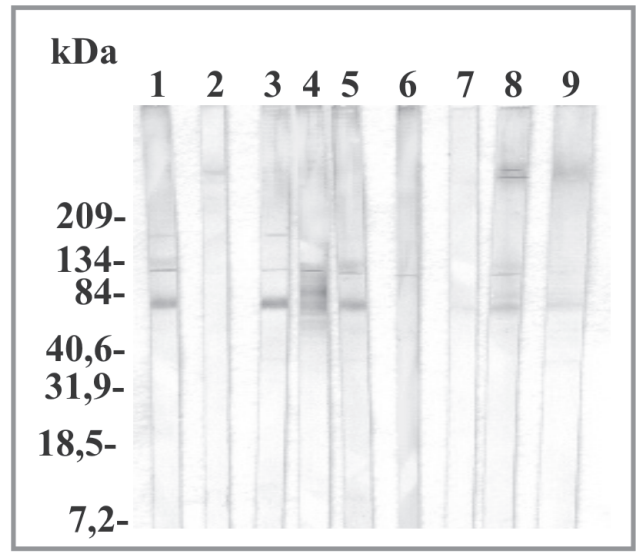

D

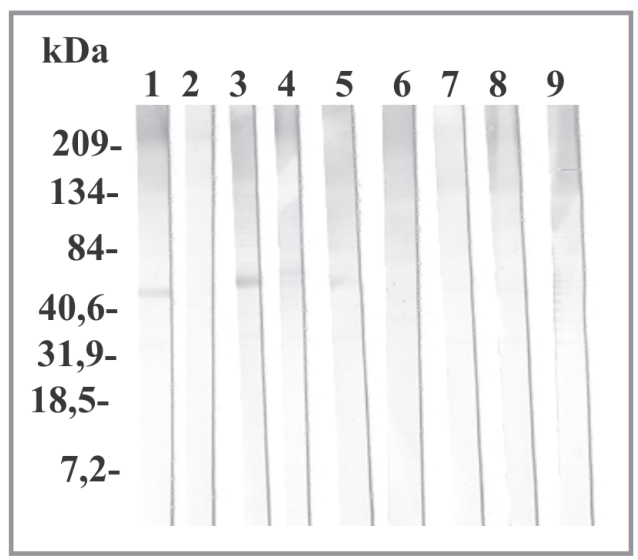

Fig. 2: immunorecognition patterns of Ig's in sera of the patients diagnosed with parasitism of 1: Loa loa, 2: Onchocerca volvulus, 3: Ascaris lumbricoides, 4: Trichuris trichiura, 5: Toxocara canis, 6: Schistosoma intercalatum, 7: S. mansoni, 8: Echinococcus granulosus, and 9: Fasciola hepatica against A: CE of Anisakis simplex (AK antigen), B: PAK antigen, C: PAS antigen, D: EAS antigen, and E: CE of A. suum (AS antigen). 


\begin{tabular}{|c|c|c|c|}
\hline \multicolumn{2}{|c|}{ CAP values } & \multirow{3}{*}{$\begin{array}{l}\text { O.D. } \\
\text { O.D. }\end{array}$} & \multirow{3}{*}{$\%$ sensitivity $=\frac{a}{a+c} \times 100$} \\
\hline $\mathrm{a}$ & b & & \\
\hline \multirow[t]{5}{*}{$\mathrm{c}$} & d & & \\
\hline & & & $\%$ specificity $=\frac{d}{b+d} \times 100$ \\
\hline & & & $\%$ predictive value: \\
\hline & & & Positive test $=\frac{a}{a+b} \times 100$ \\
\hline & & & Negative test $=$ \\
\hline
\end{tabular}

Fig. 3: calculation of sensitivity, specificity, and predictive value (positive and negative) for the different immunoglobulins (Ig's, IgG, IgM, and IgA) against crude extract of Anisakis simplex and purified antigens PAK, and PAS. The different cut points selected corresponded of values of O.D. $\geq 0.05$

tion time and the type of immunological response that the worms can provoke in the host.

In the serum from the $T$. trichiura patient the highest antibody levels detected by ELISA against the crude extract (CE) A. simplex and its purified fractions were observed when the Ig's and IgG antibodies were measured. Turner et al. (2002) mentioned that people who live in endemic areas have high levels of IgG1 and IgG4 antibodies when tested against their homologous antigen. This increase of antibodies could be related with the high $\mathrm{IgG}$ levels detected by us when the A. simplex antigen and its purified fractions were tested by ELISA, due to both parasites (A. simplex and T. trichiura) are nematodes and the high probability of existence of common proteins. However, the antigenic cross-reactivity between Ascaris and Anisakis antigens is known. Sakanari et al. (1988) suggested the existence of taxonomically related epitopes between both nematodes. Further, Iglesias et al. (1996) observed high cross-reactions among $A$. simplex and other ascarids as Hystherotylacium aduncum, T. canis and $A$. summ, indicating that neither $A$. simplex excretory-secretory nor crude extract antigen are eminently good for the serodiagnosis.

Lillywhite et al. (1991) showed the presence of crossreactions between $T$. trichiura and $A$. lumbricoides and $T$. canis when $\operatorname{IgG}, \operatorname{IgE}$, and $\operatorname{IgM}$ antibodies were measured. In the same manner, we detected in that, the serum from the $T$. trichiura patient, the presence of unspecific antibodies was higher against the A. suum than the A. simplex antigen.

In the serum of the patient diagnosed with E. granulosus infection the highest antibody levels corresponded to Ig's, IgA, and IgG. In this disease, the antibody responses during the infection are measured against the CE antigen or parcially purified hydatidic cyst fluid. Some workers have mentioned that the carbohydrated structures play an important role in the survival of some parasites (Butterworth et al. 1988, Dunne 1990, Ouaissi et al. 1991). In the E. granulosus case, $23 \%$ of the IgG re- sponses against surface protoescolex antigens are leaded by the carbohydrated epitopes (Hernández \& Nieto 1994).

When the Western blot were carried out using the $A$. simplex antigen, in the serum from the E. granulosus patient, the presence of immunoreactive bands of high molecular masses were observed when the Ig's were tested while, in the case of the PAK antigen, a band of around 60 kDa appeared.

The first purification step consisted in binding the larval $A$. simplex antigen to homologous antibodies from rabbits experimentally immunized with this antigen and eluted from the column in order to eliminate the major cross-reactive molecules. The protein patterns of the $A$. simplex crude extract (AK antigen) by SDS-PAGE showed proteins of 205, 120, 66-45, 40, 31-21, and $14 \mathrm{kDa}$. After its purification across the rabbit anti-A. simplex IgG column (PAK antigen), the same proteins were obseved but in a different proportion and, in the case of the human $\mathrm{IgG}$ column, the protein of $40 \mathrm{kDa}$ was in a high concentration (Rodero et al. 2002).

When the anti-F. hepatica serum was tested, the highest antibody levels corresponded to Ig's, IgM, IgG, and finally IgA, against the CE A. simplex antigen and its purified fractions. However, by Western blot, only appeared bands of high molecular masses, as well as, other around $30 \mathrm{kDa}$, when the $A$. simplex $\mathrm{CE}$ antigen was tested. In patients diagnosed with $F$. hepatica there are elevated IgM and IgG antibody levels, being the IgG1 and the IgG4 the most prevalent isotypes (Chen \& Mott 1990, O'Neill et al. 1998), while the IgA levels are not altered (Sampaio Silva et al. 1985).

In the sera from the patients diagnosed with $A$. lumbricoides and T. canis infections there were neither IgG nor IgA antibodies against any A. simplex antigen. However, IgM antibodies were detected which were responsible of the Ig's level augmentation. Matsumura et al. (1984) observed that anti-Toxocara circulating antibodies can be detected in puppies six months old, as well as, in adult dogs, due to an increase of IgM levels induced by small amounts of excretory-secretory materials from the larvae maintained in the tissues.

Iglesias et al. (1996) confirmed by immunoblotting the high degree of cross-reactivity between the somatic antigens of $A$. simplex and other ascaridoids, such as, A. suum, T. canis, and $H$. aduncum, although several $A$. simplex components, in the $11-18 \mathrm{kDa}$ range, were only recognized by sera from mice infected with $A$. simplex.

After the immunobloting using the T. canis and $A$. lumbricoides sera, we observed immunorecognition of proteins of high molecular mass when the CE A. simplex antigen was tested. In 1990, Maizels and Page, observed that the T. canis larva released high quantities of glycoproteins during the in vitro culture, belonging to the excretory-secretory products and Mc Williams et al. (1987) demonstrated a type I allergy cross-reaction between $A$. suum and T. canis in which the allergens responsible for the cross-reactivity were predominantly of high molecular masses.

When the PAS antigen was tested, immunoreactive bands around 40 and $30 \mathrm{kDa}$ proteins were present. When the protein pattern of the PAS antigen was studied after 
its purification using the anti-A. suum column, the unbinding proteins (specific proteins) were of $120,66-45,40$, $31-21$, and $14 \mathrm{kDa}$. Higher concentrations of specific proteins were seen compared to the unpurified samples (Rodero et al. 2002).

Finally, in both sera (T. canis and A. lumbricoides) a band around $60 \mathrm{kDa}$ appeared against the EAS antigen responsible of the cross-reaction with the A. simplex antigen. Nunes et al. (1997) detected at least one band with molecular weight around 55-66 kDa that seems to be responsible for the cross-reactivity between T. canis and A. suum, which disappears when previous absorption of the serum samples with $A$. suum antigens was performed.

Previously, the discriminating capability of both antigens (PAK and PAS) were assayed in sera from rabbits immunized with larval A. simplex or adult $A$. suum $\mathrm{CE}$ or inoculated with embryonated $T$. canis eggs and we observed that this capability for discriminate between A. simplex and A. suum was improved in the case of the PAS antigen (Rodero et al. 2002).

To calculate the sensitivity and the specificity parameters, it is neccesary to select the "gold standard" which can evaluate the accuracy of the diagnostic test on the basis that the evaluated disease is truly present of absent in the selected patients. In our case, the CAP value was selected as a "gold standard", although is not a very good diagnostic method but is routinely used to select the Anisakis sensitised patients.

The sensitivity and the specificity determinations were performed testing sera from patients diagnosed with $A$. simplex sensitisation, against the CE (AK antigen), as well as, the purified PAK and PAS A. simplex antigens, in order to observe the possible variations produced during the purification process. These evaluations were carried out against all the tested immunoglobulins (Ig's, IgG, IgM, $\operatorname{IgA}, \operatorname{IgE}$ ), to determine the working conditions (immunoglobulin and antigen) for the human anisakidosis diagnosis.

When the A. simplex crude extract was used, variations of the sensitivity and the specificty were detected according to the immunoglobulin selected. For the same cut point of O.D. $=0.15$, the sensitivity varied from values of $83 \%$, for the $\operatorname{IgG}$, to only $20.7 \%$, in the case of the $\operatorname{IgA}$. This fact showed the difficulty of the immunodiagnosis of anisakidosis when only a specific immunoglobulin type is studied.

In our experimental conditions, we showed the useful of testing the sera in a first step against the A. simplex crude extract and then carrying out a second determination against the PAK and the PAS purified antigens.

This does not imply an additional cost of time. For this, the cut point of O.D. $\geq 0.15$ for the $\mathrm{IgG}$ was selected as a first reference. This immunoglobulin showed the greater sensitivity (82.7\%). In the first step of the diagnostic investigations the sensitive tests are the most useful (Fletcher et al. 1998). When this parameter was applied, $70 \%$ of the sera were positive, in spite of all the sera except one that had a CAP value $\geq 2$. The CAP System has a poor specificity and shows a high rate of false positive results. This fact was also observed by Lorenzo et al. (2000) when evaluated several immunological techniques in order to make the diagnosis of Anisakis allergy, observing $50 \%$ of specificity with the CAP system assay.

The second determination was performed by using the PAK antigen and the cut point of O.D. $\geq 0.07$ for the IgG. This value was selected because in the middle of the diagnostic investigation, showed medium values of specificity and sensitivity ( 58.6 and $54.5 \%$, respectively). When all the assayed sera were evaluated, a decrease of $20 \%$ in the positive group was observed. Only two sera, previously negative against the $A$. simplex crude extract, were maintained positive. These results are in accordance with the high predictive value (80\%) observed in the A. simplex crude extract, although a probability of $20 \%$ (six sera) of the existence of false positive results is always present. In our case the decrease observed was greater (from 28 positive sera for A. simplex crude extract to 20 for the PAK antigen).

Finally, the cut point of O.D. $\geq 0.05$ for the $\operatorname{IgA}$ was selected against the PAS antigen. This immunoglobulin showed the highest specificity $(81.8 \%)$ and predictive value $(88.9 \%)$.

Likewise, for the detection of $\operatorname{IgA}$, a little amount of serum $(1 \mu \mathrm{l})$ is required in contrast to the $\mathrm{IgE}$, in which case $200 \mu \mathrm{l}$ of serum are necessary.

When these parameters were applied, only seven of the 38 tested sera were positive. All these sera were also positive against both the A. simplex $\mathrm{CE}$ and the PAK purified antigens.

When the cut points were selected, we applied these parameters to the sera from the patients diagnosed of several parasitic infections and we observed that, against the AK antigen (O.D. $\geq 0.15$ for the $\operatorname{IgG}$ ), the sera from the patients diagnosed with parasitisms by L. loa, T. trichiura, S. intercalatum, E. granulosus, and F. hepatica were positive. This fact indicated the presence of common antigenic proteins among the Anisakis antigens and other parasites. Likewise, one of the fundamental aspects of the immunodiagnosis is the selection of adequate antigens to carry out the diagnostic tests.

When the sera were tested against the PAK antigen $(\mathrm{OD} \geq 0.07$ for the $\operatorname{IgG})$, the same sera were positive again but, when the third determination was carried out using the PAS antigen ( $\mathrm{OD} \geq 0.05$ for the $\operatorname{IgA})$, only were positive the sera from the patients diagnosed with parasitisms of E. granulosus and F. hepatica. Previously, we had observed this same fact, when the capability of the different antigens to discriminate among the sera from the patients diagnosed with several parasitic infections were determined, when the lowest values were detected using the anti-Echinococcus or anti-Fasciola sera. It is necessary to mention that, in the purification process of the A. simplex antigen, an hyperimmnune serum from rabbits immunised with $A$. suum was used and no sera from animals immunised with the other parasites that are infecting the different patients utilised in this assay. However, a remarkable augmentation of the sensitivity and specificity in the fractions of $A$. simplex antigen purified, was appreciated. 


\section{REFERENCES}

Águila C, Cuéllar C, Fenoy S, Guillén JL 1987. Comparative study of assay detecting circulating immune-complexes and specific antibodies in patients infected with Toxocara canis. J Helminthol 61: 196-202.

Bradford M 1976. A rapid a sensitive method for the quantitation of microgram quantities of protein utilizing the principle of protein-dye-binding. Ann Biochem 72: 248.

Butterworth A, Dunne D, Fulford A, Capron M, Koch D, Ouma J, Sturrock R 1988. Immunity in human schistosomiasis mansoni: cross-reactive $\operatorname{IgM}$ and $\operatorname{IgG} 2$ anticarbohydrate antibodies block the expression of immunity. Biochemistry 70: 1053-1063.

Cuéllar C, Fenoy S, del Águila C, Guillén JL 1990. Evaluation of chemotherapy in experimental toxocarosis by determination of specific immune complexes. J Helminthol 64: 279289.

Chen MG, Mott KE 1990. Progress in morbidity due to Fasciola hepatica infection. Trop Dis Bull 87: 1-37.

Dune D 1990. Schistosome carbohydrates. Parasitol Today 6: 45-48.

Fletcher RH, Fletcher SW, Wagner EH 1998. Epidemiología Clinica. Aspectos Fundamentales, Masson-Williams \& Wilkins, Barcelona

García-Palacios L, González ML, Esteban MI, Mirabent E, Perteguer MJ, Cuéllar C 1996. Enzyme-linked immunosorbent assay, immunoblot analysis and RAST fluoroimmunoassay analysis of serum responses against crude larval antigens of Anisakis simplex in a Spanish random population. J Helminthol 70: 281-289.

Guillén JL, Cuellar C, del Águila C 1986. Fotodependencia del desarrollo embrionario de Toxocara canis (Werner, 1782). Stiles, 1905. Rev Ibér Parasitol 46: 67-74.

Hames BD 1986. An introduction to polyacrilamide gel electrphoresis. In BD Hames, D Rickwood (eds), Gel Electrophoresis in Proteins, IRL Press, Oxford.

Hernández A, Nieto A 1994. Induction of protective immunity against murine secondary hydatidosis. Parasite Immunol 16: $537-544$.

Iglesias R, Leiro J, Ubeira FM, Santamarina MT, Navarrete I, Sanmartín ML 1996. Antigenic cross-reactivity in mice between third-stage larvae of Anisakis simplex and other nematodes. Parasitol Res 82: 378-381.

Ishikura H, Kikuchi K, Nagasawa K, Ooiwa T, Takamiya H, Sato N, Sugane K 1993. Anisakidae and Anisakiosis. In T Sun, Progress in Clinical Parasitology, Springer-Verlag, New York.

Kennedy MW, Tierney J, Ye P, McMoanagle FA, McIntosh A, McLaughlin D, Smith JW 1988. The secreted and somatic antigens of the third stage larva of Anisakis simplex, and antigenic relationship with Ascaris suum, Ascaris lumbricoides, and Toxocara canis. Mol Biochem Parasitol 31: 35-46.

Laemmli UK 1970. Cleavage of structural proteins during the assembly of the head of bacteriophage T4. Nature 227: 680-685.

Lillywhite JE, Bundy DA, Didier JM, Cooper ES, Bianco AE 1991. Humoral immune responses in human Infection with the whipworm Trichuris trichura. Parasite Immunol 13: 491-507.

Lorenzo S, Romaris F, Iglesias R, Audícana MT, Alonso J, Leiro J, Ubeira FM 2000. O-glycans as a source of cross-reactivity in determinations of human serum antibodies to Anisakis simplex antigens. Clin Exp Allergy 30: 551-559.

Maizels RM, Page AP 1990. Surface glycoproteins from Toxocara canis larvae parasites. Act Trop 47: 355-364.

Mc Williams AS, Stewart GA, Turner KJ 1987. An immunological investigation of the allergens from Ascaris suum perienteric fluid. Cross-reactivity, molecular weight distribution and correlation with phosphorilcholine-containing components. Int Arch Allergy Appl Immunol 82: 125-132.

Matsumura K, Kazuta Y, Endo R, Tanaka K 1984. Detection of circulating toxocaral antigens in dogs by sandwich enzymeimmunoassay. Immunology 51: 609-613.

Noya O, Fermin Z, Alarcon de Noya B, Losada S, Clomenares C, Hermoso T 1995. Humoral immune response of children with chronic schistosomiasis. Isotype recognition of adult worm antigens. Parasite Immunol 17: 319-328.

Nunes CM, Tundisi RN, García JF, Heinemann MB, Ogassawara S, Richtzenhain LJ 1997. Cross-reactions between Toxocara canis and Ascaris suum in the diagnosis of visceral larva migrans by western blotting technique. Rev Inst Med Trop São Paulo 39: 253-256.

O'Neill SM, Parkinson M, Strauss W, Angles R, Dalton JP 1998. Immunodiagnosis of Fasciola hepatica infection (fasciolosis) in a human population in the Bolivian Altiplano using purified cathepsin L cysteine proteinase. Am J Trop Med Hyg 58: 417-423.

Ouaissi MA, Taibi A, Loyens M, Martín U, Afchain D, Maidane C, Cardioti C, Cornete J, Martelleur A, Velge P 1991. Trypanosoma cruzi: a carbohydrate epitope defined by a monoclonal antibody as a posible marker of the cute phase of human Chaga's disease. Am J Trop Med Hyg 45: 214-225.

Perteguer MJ, Cuéllar C 1998. Isotype-specific immune responses in murine experimental anisakiasis. J Vet Med 45: 603-610.

Rodero M, Jimenez A, Chivato T, Laguna R, Cuellar C 2001. Purification of Anisakis simplex antigen by affinity chromatography. Parasitol Res 87: 736-740.

Rodero M, Jiménez A, Cuellar C 2002. Evaluation by ELISA of Anisakis simplex larval antigen purified by affinity chromatography. Mem Inst Oswaldo Cruz 97: 247-252.

Sakanari JA, Loinaz M, Deardorff TL, Raybourne RB, McKerrow JH, Frierson JG 1988. Intestinal anisakiasis. A case diagnosed by morphological and immunologic methods. Am J Clin Pathol 90:107-113.

Sakanari JA, McKerrow JH 1989. Anisakiasis. Clin Microbiol Rev 2: 278-284.

Sampaio Silva ML, Vindimian M, Wattré P, Capron A 1985. Etude des anticorps IgE dans la distomatose humaine á Fasciola hepatica. Pathol Biol 33: 746-750.

Turner J, Faulkner H, Kamgno J, Else K, Boussinesq M, Bradley JE 2002. A comparison of cellular and humoral immune responses to trichuroid derived antigens in human trichuriasis. Parasite Immunol 24: 83-93.

Welch JS, Symons MH, Dobson C 1983. Immunodiagnosis of parasitic zoonoses: purification of Toxocara canis antigens by affinity chromatography. Int J Parasitol 13: 171-178. 
